\title{
Genocidal sexual assault on women and the role of culture in the rehabilitation process: Experiences from working with Yazidi women in Turkey
}

\author{
Sahika Yüksel*, Suzan Saner**, Ayse Devrim Basterzi***, Zerrin Oglagu****, \\ Israfil Bülbül*****
}

\section{Introduction}

Sexual assault against women and girls is frequently used as a strategic weapon during war. The conflicts in Bosnia, Sierra Leone, Peru, Somalia and Cambodia demonstrate that sexual violence and rape of women often occurs when war is ongoing; enslavement, sexual violence, trafficking, forced marriage and pregnancy, and forced conversion and assimilation are some of the genocidal sexual assaults and human rights abuses committed (UNHCR, 2003). Genocidal sexual assaults seek to destroy the target group's biological and cultural identity, and the social fabric of a community: the way the community relates to itself and its members can be profoundly damaged as a result (Gottschall, 2004). Warring factions aim to humiliate their adversaries by assaulting women affiliated with the opposition. More indirectly, women's risk of sexual assault increases during war due to the changing living conditions, migration routes and insecure sheltering conditions.

\footnotetext{
*) Istanbul University, Medical Faculty, Psychiatry Dept. Istanbul, Turkey.

$\star \star$ ) Independent psychiatrist

$\star \star \star)$ Ass. Prof. Psychiatrist, Private Office, Istanbul, Turkey.

$\star \star \star \star)$ Psychiatrist, Private Office, Istanbul, Turkey.

$\star \star \star \star \star$ ) Psychiatrist, Private Office, Diyarbakır, Turkey

Correspondence to: sy4650@gmail.com
}

In Syria, as with other countries in the region, women may be killed due to 'honor' killings after they've been raped; however, husbands rarely define rape as a crime, which contributes to under-reporting. However, as documented in virtually every governorate countrywide, it is known that sexual and gender-based violence including rape, sexual assault, sexual torture and sexual humiliation has increased in tandem with the growing numbers of warring parties in the ongoing conflict (Human Rights Council, 2018). Indeed, rape has been identified as one of the main reasons for leaving the country (Human Rights and Gender Justice (HRGJ, 2016; MAZLUMDER, 2014).

Sexual violence often leads to posttraumatic stress disorder, depression, anxiety disorders, and other adverse conditions amongst victims. Family members and loved ones, or witnesses to the act, are also impacted. Yazidis, a group characterised by practicing an ancient religion that contains elements of Zoroastrianism, Judaism, Christianity, and Islam, were targeted by so called Islamic State of Iraq and Al-Sham (ISIS) in Northern Iraq in 2014. As a result of the targeted attack on women and girls living in the area of Mount Sinjar, many were kidnapped and forced into sexual slavery and killed. An estimated 4,000 people fled their homes in Iraq and took refuge in Turkey. 
This article explores the authors' observations from providing psychosocial support services to Yazidi refugee women who fled to Turkey. The themes that are forwarded were shaped by clinical experiences as well as clinical discussions amongst the team. These themes, we argue here, are relevant to actors working with specific cultural groups to advocate for and help rehabilitate survivors of sexual and gender-based torture.

\section{Historical and contextual background}

In an attempt to 'purify' the region from the non-Islamic influences, ISIS launched an offensive in Northern Iraq in 2014, executing thousands of Yazidi men and elderly women in the process. 300,000 Yazidis fled, they killed and kidnapped women and girls living in Mount Sinjar, and more than 6,000 women and children were forced into slavery, a subjugation that led to systematic mass rape (Cetorelli et al., 2017). One Amnesty International (2014) report detailed the multiple traumas that ISIS inflicted, which included ethnic cleansing of Yazidis in Northern Iraq and the mass raping of women and young girls. Those who suffered sexual assault or other violent attacks were often unable to access sufficient help when they first reached a safe haven. A report by the Commission of Inquiry determined, unsurprisingly, that ISIS's abuse of Yazidis amounted to crimes against humanity and war crimes (OHCHR, 2016). The same report also identified that over 3,200 Yazidi women and children were still being held by ISIS. Today, the majority reside in Syria where Yazidi females continue to be sexually enslaved, whilst Yazidi boys are indoctrinated, trained, and used in hostilities. Thousands of Yazidi men and boys are missing and the genocide of the Yazidis is on-going.

\section{The history of genocides and the culture of Yazidis}

The Yazidis practice an ancient religion that contains components of Zoroastrianism, Judaism, Christianity and Islam (AsherSchapiro, 2014). Their total population is less than 1.5 million and they live mainly in Iraq, Syria, Turkey and Armenia. The largest Yazidi community, approximately 400,000 people, resided in the area of Mount Sinjar, some 150 kilometers west of Mosul in Nineveh governorate (OHCR, 2016). As one of the most vulnerable and impoverished communities in Iraq, Yazidis are a closed community with a long history of being persecuted and first faced accusations of devil worship by Muslims in the late 16th and early 17 th centuries. Khanna Omarkhali, a religious researcher of Yazidi descent, states that "Extermination, emigration, and settlement of this community will bring tragic transformations to the Yazidi religion" and Matthew Barber, a scholar of Yazidi history at the University of Chicago who interviewed Yazidi refugees, asserts that "Yazidis often say they have been the victim of 72 previous genocides, or attempts at annihilation...(and) memory of persecution is a core component of their identity" (Asher-Schapiro, 2014). Having suffered from decades of discrimination, marginalization and neglect during Saddam Hussein's regime, in recent years, they have experienced increasing persecution by Sunni extremists (Suvari, 2013).

Understanding Yazidis' social structure helps to reveal how they perceive sexuality and rape. They follow a caste social stratification system and, as often observed in the Middle East, there is a large family 
model and a strict system of patriarchy. Endogamy is practiced based on very strict rules. Marrying or having sex with a nonYazidi is a reason for excommunication and sexual intercourse before marriage is forbidden for women, whilst adultery can lead to both parties being cast out of the community or even killed (Kizilhan 2018). However, an exception was made for women raped by ISIS assaults after the 2014 attacks when the leader of the Yazidis blessed these women and their families. Although an attempt was made to prevent raped women from being excommunicated or ostracized by their families, allowing children that were conceived during rape into the community remains a taboo. These children are sent to orphanages, without the women's consent, and mothers who want to be reunited with their children are, consequently, ostracized from the community (Bor, 2018).

\section{Experiences of the Turkish Human Rights Foundation Psychosocial Support Program of Yazidis}

The event and traumatic migration

ISIS launched a coordinated attack on Sinjar City and surrounding towns and villages, forcing Yazidis to seek refuge on Mount Sinjar on August 2014. Whoever could not flee in time were either killed or kidnapped and tens of thousands of Yazidis remained trapped without water, food, or shelter in temperatures rising above $50^{\circ} \mathrm{C}$. Once a safe corridor was opened, most Yazidis were evacuated between August $9^{\text {th }}$ and $13^{\text {th }}$, allowing them to flee through Syria into the Kurdistan region of Iraq and Turkey. They could not access any food, shelter or clean water during the migration period and many people, particularly the most vulnerable such as babies and children, died of thirst during this journey (Cetorelli et al., 2017).
Diyarbakir Municipality: The local context Upon arrival in Turkey, the Diyarbakir Municipality provided shelter for Yazidis and supplied their basic daily needs. Fidanlik campground was only 25 kilometres away from Diyarbakir city centre and it hosted around 4,000 people in the first year, but the population decreased with time as people found opportunities to go to other countries or returned to their own countries. By May 2015, there were 900 people under the age 18 and the male-female ratio in the total population was broadly equal. The camp had laundry facilities, a cafeteria, a building for social activities, tents and adequate numbers of baths, bathrooms, and fountains with drinking water. A median of four people stayed in each tent and relatives lived in close proximity. The camp was administered together with municipality workers and members of the Yazidi society, and municipal police worked outside the camp area. There was also a well-equipped infirmary, a pharmacy and a 112 emergency help stations within the camp. In addition to volunteers, first level health care services were provided by the Diyarbakir chamber of physicians, the union of health workers, and doctors worldwide; health care services were also provided by the Ministry of Health through temporary agreements with general practitioners $^{1}$ (THRF, 2016). Yazidis were unable to receive free medical aid from state hospitals in Diyarbakir because they were not granted legal refugee status in Turkey.

Overview of the support program The Turkish Human Rights Foundation (THRF) set up the Psychosocial Support

1 B. Doğru (personal communication, 15 November, 2016) with Psychologist of Turkish Human Rights Foundation (TIHV). 
Program (PSSP) for the Yazidis - 'YazidisPSSP'- in Diyarbakir. Psychosocial support and treatment were provided by mental health professionals who were THRF volunteers and came from the local area. Psychosocial support program studies were conducted with an interdisciplinary team of volunteers comprised of psychologists, psychiatrists, social workers, psychological counsellors, and teachers. The team conducted regular supervision and information sharing meetings every two weeks. Although these volunteers had varying degrees of experience with working with survivors of trauma, they all had previously worked with the THRF and were familiar with human rights work.

Before the team began delivering the PSSP at the camp, a training workshop for volunteers was delivered which focused on: sexual abuse evaluation problems; the difficulties and many conflicts that might arise for those experiencing assault as well as their families and their community; and the role of mental health experts who are trying to treat the victims (THRF, 2016). Discussions on how to deliver services through a feminist framework were also held.

The program was divided into two groups: adults and children between the ages of 5-17. Social and educational activities for the children were prioritized and psychological and psychiatric meetings were conducted for both groups when needed. As part of the process, between 30 to 60 people were evaluated for psychological treatment every month, an assessment which was done every week for the first six-month period. In total, around 600 meetings were held and circa 200 patients were evaluated and $65 \%$ of those who applied for meetings were women. ${ }^{2}$ Mental health care was also provided to people whose loved ones had been abducted; a number of close relatives and friends were still missing. These meetings motivated others to seek mental health counselling as awareness of these support services increased through word of mouth, and between 7 and 10 meetings were held in the camp five days a week (THRF, 2016).

Physical complaints and requests for medical help were communicated easily and pre-existing mental health problems such as mental retardation (MR), psychosis, bipolar disorder and epilepsy were diagnosed and treatments were regulated (Güler, 2016). However, it was challenging for people to discuss their sexual violence experiences. When factors such as migration, assaults, war and loss were interwoven with the closed, hierarchical and patriarchal society of the Yazidis, it compounded a situation where women had trouble expressing themselves in many cases. In short, there were considerable barriers to communicating with Yazidi refugee women on sexual rights and their own bodies.

Developments in the Yazidi camp after two years Although during the first few months the residents of the camp didn't leave, some of the Yazidis subsequently started working in the city, and most of the Yazidis eventually left for other places, often Europe. After two years, around 1,000 people still remained in Diyarbakir - mostly women, the elderly and children. Two suicides were identified, both of which were women, and it was later established that these women were in contact with non-Yazidi men. Although the full nature of the relationships was unclear, their families disapproved and anecdotal sources suggested that their suicides were associated with the war (Güler, 2016).

Over time, distrust diminished. The PSSP volunteers speak the same language (Kurdish) which allowed them to communicate with the Yazidis without 
a translator and the quality of interactions improved over time. The project progressed from first helping them to stabilize in the new environment and building up trust, to starting-up play activities for children. Until November 2015, the program undertook closed group work with 250 children once a week (THRF, 2016) and English classes were particularly attractive for those younger people who wished to go to European countries. Some Yazidis have been in continuous psychiatric counselling with volunteer local psychiatrists. Individuals with severe trauma-related problems frequently expressed their complaints with somatic problems like pain, insomnia, restlessness, tiredness, and irritability: for when a person is silent, the body may speak (Sigurdardottir \& Halldorsdottir, 2013).

Some Yazidis were often willing to talk about what happened in the past, in general terms, and the difficulties they faced. They complained about not being able to go to Europe, but still possessed a continual desire desired to go. They were thus reluctant to learn the Turkish language. However, most were not ready to talk about their personal traumatic experiences and their associated feelings and issues and only sought medication. Below is a case report that helps to illustrate the context, symptoms and health care journeys that many faced:

"A 24-year old married woman applied to the outpatient service. She was illiterate. She was living in a refugee camp with her husband and child. Her parents and siblings were living in Iraq and her brother-in-law had been murdered by ISIS three years ago. One year ago, after their village was captured by ISIS; she, her husband and their child left the village under cover of the darkness of night. She was avoiding social contact and suffering shivering, headaches, sleep problems, easily getting angry, and loss of appetite. Although she reported irritability prior to the escape, currently there has been a substantial increase. She was prescribed antidepressants (mirtazapine 30mg/d and duloxetine 30mg/d) and a follow up every 2nd week. She did not disclose her feelings. In the treatment process her problems decreased."

How did social norms and values affect professional relationships with victims? People working within the Yazidi camp and the professionals, who came to give psychosocial support, were from a Muslim majority country and it was Muslim extremists who had displaced the Yazidis and committed atrocities in the name of Islam. In the Yazidi community, which is generally closed to outsiders, relations with non-Yazidi communities is mostly conducted by highranking men in the communal hierarchy. In this context, obtaining information about women was challenging, particularly in the light of the caste system and gender hierarchy and information about women could only be attained from community leaders and elders and their male family members. Decisions about a woman's life appeared to be always made by men, but women who had health problems - such as fainting, pain, numbness, tremors and palpitations associated with traumas-were allowed to visit doctors.

Multiple reasons for not being able to undertake the usual individual trauma therapies with the Yazidis were identified. Firstly, inhibited cognition and comprehension was observed due to exhaustion, poverty and illiteracy. The considerable cultural differences and the concept of psychotherapy being alien to most Yazidi women were other key challenges. Yazidi culture is very communal and there is little acceptance of this type of individual reflection, especially among 
women. Many of the women experienced trauma, which was caused by their recent traumas as well as historical ones, as Yazidis have been the object of multiple genocides. This combination of historic and more recent traumas makes treatment particularly challenging. Yazidis are very different when compared to other patients, who generally request psychiatric assistance by their own volition (Kizilhan, 2018; UNHRC, 2015). Their traumatic life events also continued in Turkey where they experienced multiple traumatic events in the Turkish-Kurdish region. There have been suicide bombings, detainments, and other violent attacks. Being regularly exposed to these events on television, as well as witnessing them on the streets, increased their anxiety and feelings of trauma.

It is also difficult to explain sexual assault in most situations, but it's even harder to explain it while living in camp conditions in a foreign country as a result of war and displacement. Moreover, although it has been suggested that women's social position could improve post-migration due to greater opportunities for empowerment, compared to the place where they emigrated from (Hardi, 2005), the sexism of their own society, coupled with the racism of the place they migrated to, produces a challenging milieu for immigrant women to navigate and may increase anxiety and pressure. During the Yazidis-PSSP, workers attempted to work within a feminist framework, with clinical sensitivity, and espouse the behaviour and language that aligned to this approach. This framework was fostered amongst all the volunteers who communicated with Yazidi women and the education team. Although measurable outcome data was not collected, which admittedly limits the objective validity of any claims, the narratives suggest that positive effects were achieved (Dinç, 2017).
It is also well established that treatments that encourage storytelling and building a narrative are effective when working with torture survivors and persons that have been forced to migrate (Dinç, 2017; Hardi, 2015).

\section{Further reflections and conclusions}

Despite the link between gender-based violence and other acts of violence to women being observed throughout history, particularly in the last 50 years, it has only been possible to understand and analyze them comparatively recently. Historically, this has been neglected in research, which perhaps reflects patriarchal structures within academia itself. However, feminists are working to address this and must continue to do so as rape during war is a complicated, and often nuanced and feminist theory, the theory of cultural pathology or the strategic rape theory alone are not sufficient to fully understand it. An integrative approach is needed (Gottschall, 2004).

By disclosing sexual assault and pursuing legal action in the hope of obtaining justice, the person disclosing the sexual assault can face negative reactions and may even face the threat of death. Fear of such reactions makes it problematic for survivors of sexual assault to disclose what they have suffered. It is also difficult for professionals. Professionals cannot always protect women against harm as events take place outside of the professionalpatient interactions which are outside of their control; for example, if the community or the family finds that a woman has been sexually assaulted, their lives may be in danger. Such horrific instances are often referred to as so called 'honor killings'. However, this phrase must be eschewed as it obfuscates the complex processes that lead to the offense and channels the perception of the atrocity through the eyes of the murderer rather than the victim. In other words, the perpetrator's 
crime is allowed to be, at least in name, veiled with the sense that the motive was somehow honorable, an assumption that relies on male privilege. It also conjures the sense of male ownership over women, thereby implicitly (re)producing patriarchal norms in the process. Although an extreme case, the vocabulary used to frame and report on sexual violence requires greater care and sensitivity. Words matter and the obvious and subtler forms of patriarchal meaning that such terms are imbued with must be challenged.

Furthermore, understanding the social structure of a society is critical to uncovering the meaning of sexual abuse, but it is also not sufficient alone. Historically, it's been reported that the cultural and religious construct dominating the sexual embodiment of women is a 'discourse of shame' that results in silence and secrets. It is also essential to better describe the creation of immigrant women's sexual embodiment and to understand their experiences and sexual knowledge in order to heal and to ease their sexual autonomy (de Jong, 2011). The following social values are therefore critical to grasp: how sexuality is constructed as young girls reach adulthood; the conveyance of sexual knowledge of women and mothers to girls in the family; how sexual knowledge is communicated within the society; the concept of virginity; the conception of sexual behavior among sexes; and how consent to sexual intercourse is defined within a relationship and marriage. Uncovering how sexuality is discussed and how regularly is therefore key. As illustrated through our work with Yazidis, understanding what the sexual discourse is among Yazidis, a closed society, is necessary to evaluate the effects of rape and sexual violence on Yazidi individuals and society more broadly. This is of course a demanding undertaking as it takes considerable time to develop a sense of trust. It is, however, hoped that the learnings and reflections of our experience with working with Yazidi women will resonate with those workings in other contexts and provoke further reflection.

Finally, decoding the interconnected nature of women's sexuality, sexual trauma and their human rights through a gender sensitive approach, whilst being sympathetic to social and cultural nuances, is a vital component in providing optimal support and counselling to refugees from different cultures. Legislation, law and statutes do not go far enough in this regard.

To make a broader point, legislation, law and the conditions of international agreements such as the signed agreement of the prevention of all kinds of discrimination against women (UN- CEDAW) ${ }^{2}$ and the most recent and comprehensive text on the struggle against violence against women and discrimination based on gender (The İstanbul Agreement) ${ }^{3}$ must be complemented by the vast knowledge and experience of women's organizations, professional chambers, and specialty foundations working in these fields at more operational levels. Only by working together can the appropriate policies, reparation procedures, and holistic rehabilitation services be designed and delivered to best help survivors of sexual and gender-

2 See United Nation (1979) Convention on the Elimination of All Forms of Discrimination Against Women (CEDAW). Retrieved from http://www.un.org/womenwatch/daw/cedaw/

3 See The İstanbul Convention (2011) The Convention on Preventing and Combating Violence Against Women and Domestic Violence. Retrieved from https://www.coe.int/en/web/istanbul $\% 20$ convention/home?\%2520 
based torture. Optimizing the effectiveness of evaluation, diagnosis, treatment and rehabilitation against sexual violence ultimately requires an environment where sexism can be challenged, is challenged, and is then eradicated. Regarding this broader ambition, a lot more work needs to be done.

\section{Acknowledgements}

The authors are grateful to the dedicated and courageous organisations, volunteers, friends and Yazidi women who inspired the work discussed here in this article.

\section{References}

Amnesty International Annual Report. (2015). Amnesty International Annual Report 2014/15. Retrieved from https://www.amnesty.org/en/latest/ research/2015/02/annual-report-201415/

Asher-Schapiro, A. (2014). Who Are the Yazidis, the Ancient, Persecuted Religious Minority Struggling to Survive in Iraq? National Geographic. Retrieved from http://news. nationalgeographic.com/news/2014/08/140809iraq-yazidis-minority-isil-religionhistory/

Bor, G. (2018). Ylkılamayan Tabu: Tecavüzden Doğan Çocuklar (Indestructible taboo: Children born from rape). Bianet. Retrieved from https:// bianet.org/bianet/toplumsal-cinsiyet/196176yikilamayan-tabu-tecavuzden-dogan-cocuklar

Cetorelli V, Sasson I, Shabila N, Burnham G. (2017). Mortality and kidnapping estimates for the Yazidi population in the area of Mount Sinjar, Iraq, in August 2014: A retrospective household survey. PLoS Med 14(5): e1002297. https://doi. org/10.1371/journal.pmed.1002297

de Jong, K. (2011). Psychosocial and mental health interventions in areas of mass violence: $A$ community-based approach. Second Edition. MSF, Amsterdam, p.66-74.K

Dinç NK. (2017). Kanatlarn Gölgesinde: Şengal Dile Gelirse (Shadow of Wings: If Sinjar Going to Speak). Zan Vakfi Yayınları, İstanbul.

Güler, S.(2016). Diyarbakır Fidanlik Alanında Ezidilerle Yapulan Psikososyal Destek Calısmasindan Edinilen Deneyimler, Türkiye Insan Haklan Vakfi. (Learning Lessons from Psychosocial Support Project in Diyarbakir, Fidanlik. Turkish Human Rights Foundation. Ankara. Retrieved from http://tihv. org.tr/wp-content/uploads/2017/02/EzidilerT\%C3\%BCrk\%C3\%A7e.pdf
Gottschall J (2004) Explaining war time rape. The fournal of Sex Research, 41(2):129-136. https:// doi.org/10.1080/00224490409552221

Hardi, C. (2005). "Kurdish Women Refugees: Obstacles and Opportunities" in Forced Migration and Mental Health: Rethinking the Care of Refugees and Displaced Persons. David Ingleby (ed.). Springer Science \& Business Media, New York/ USA.

Human Rights and Gender Justice (HRGJ). (2016, March). Human Rights Violations Against Women and Girls in Syria. Paper submitted at United Nations Universal Periodic Review of the Syrian Arab Republic 26th Session of the UPR Working Group of the Human Rights Council. Retrieved from https://www.madre. org/sites/default/files/PDFs/Syria\%20UPR $\% 20$ submission $\% 20$ Final.pdf

Human Rights Council. (2018, March) 2018. "I lost my dignity": Sexual and gender-based violence in the Syrian Arab Republic. Paper presented at the conference on Independent International Commission of Inquiry on the Syrian Arab Republic (A/HRC/37/CRP.3). Retrieved from https://reliefweb.int/sites/reliefweb.int/files/ resources/A-HRC-37-CRP-3.pdf

Kizilhan Jí, Bor, G. (2018). Êzidî Kadınlar Çok Güçlü; Bunun Sebebi Kuşaklar Arası Travma (Yazidis women are powerful: Because of transgenerational traumas. Bianet. Retrieved from https://bianet.org/bianet/toplumsalcinsiyet/199681-prof-kizilhan-ezidi-kadinlar-cokguclu-bunun-sebebi-kusaklar-arasi-travma

MAZLUMDER. (2014 May). The report on Syrian woman refugees living out of the camps. Retrieved from http://istanbul.mazlumder.org/webimage/ files/The $\% 20$ Report $\% 20$ on $\% 20$ Syrian $\% 20$ Women\%20Refugees(1).pdf

Mohammadi, D. (2016). Help for Yazidi survivors of sexual violence. The Lancet Psychiatry, 3(5), 409-410. https://doi.org/10.1016/S22150366(16)30004-9

OHCHR. (2016). The Commission of Inquiry Report "They came to destroy": ISIS Crimes Against the Yazidis. A/HRC/32/CRP.2. Retrieved from https://www.ohchr.org/en/NewsEvents/Pages/ DisplayNews. aspx? NewsID $=20113$

Sigurdardottir, S., \& Halldorsdottir, S. (2013). Repressed and silent suffering: Consequences of childhood sexual abuse for women's health and well-being. Scandinavian journal of caring sciences, 27(2), 422-432. https://doi.org/10.1111/ j.1471-6712.2012.01049.x

Suvari, ÇC. (2013). Ezidiler - Etnodinsel Bir İnanç Olarak Ezidilik (Yazidis - As an Ethnocentric Faith). Utopya Yayınları. 
Turkish Human Rights Foundation (THRF).

Çalişma Raporu 2015/16. Retrieved from http://

tihv.org.tr/wp-content/uploads/2017/11/2016\%C 3\%87al\%C4\%B1\%C5\%9Fma-Raporu.pdf

United Nations High Commissioner for Refugees (UNHCR). (2003) Sexual and Gender-Based Violence against Refugees, Returnees and Internally Displaced Persons: Guidelines for prevention and response. Geneva. Retrieved from http:// www.unhcr.org/protection/women/3f696bcc4/ sexual-gender-based-violence-against-refugeesreturnees-internally-displaced.html

United Nations High Commissioner for Refugees (UNHCR) (2015) Specific expressions and idioms in the Syrian context. In Culture, Context and the Mental Health, and Psychosocial Wellbeing of Syrians. Geneva. Retrieved from https://www. unhcr.org/55f6b90f9.pdf 